\title{
Publisher Correction: A square-root topological insulator with non-quantized indices realized with photonic Aharonov-Bohm cages
}

Mark Kremer (D, loannis Petrides, Eric Meyer (D), Matthias Heinrich, Oded Zilberberg (1D \& Alexander Szameit (D)

Correction to: Nature Communications https://doi.org/10.1038/s41467-020-14692-4, published online 14 February 2020.

The original version of this article had an error in Fig. $4 \mathrm{~d}$. On the upper-left side of the equation " $E= \pm 2 t$ ", The " $\mp$ " sign was mistakenly typed as a " \pm " sign. A correct Fig. 4 is supplemented with this correction. This error has been corrected in both the PDF and HTML versions of the article.

Published online: 08 April 2020

\begin{abstract}
(c) (i) Open Access This article is licensed under a Creative Commons Attribution 4.0 International License, which permits use, sharing, adaptation, distribution and reproduction in any medium or format, as long as you give appropriate credit to the original author(s) and the source, provide a link to the Creative Commons license, and indicate if changes were made. The images or other third party material in this article are included in the article's Creative Commons license, unless indicated otherwise in a credit line to the material. If material is not included in the article's Creative Commons license and your intended use is not permitted by statutory regulation or exceeds the permitted use, you will need to obtain permission directly from the copyright holder. To view a copy of this license, visit http://creativecommons.org/licenses/by/4.0/.
\end{abstract}

(c) The Author(s) 2020 

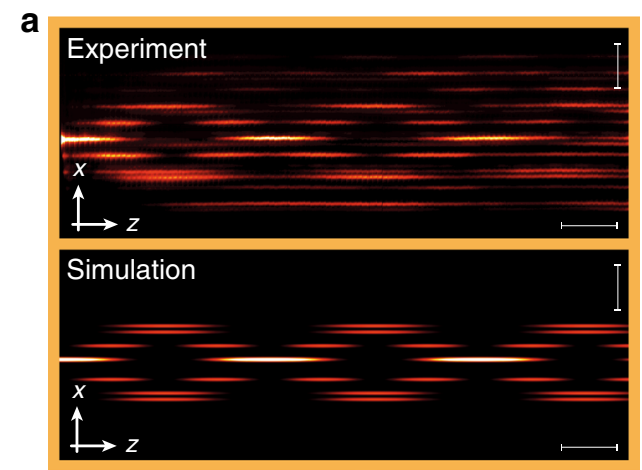

b

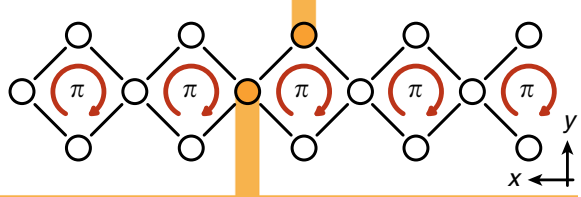

\section{Experiment}
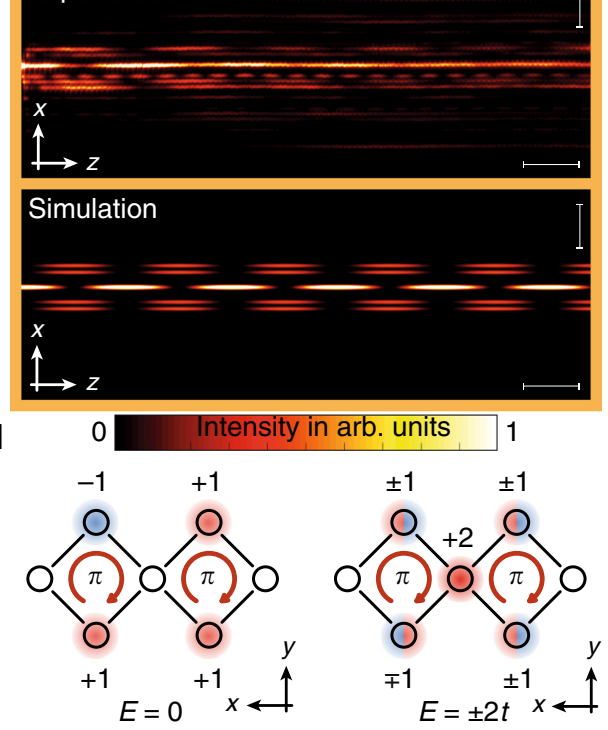

Fig. 4 